\title{
Resveratrol is an arginase inhibitor contributing to vascular smooth muscle cell vasoconstriction via increasing cytosolic calcium
}

\author{
CHANG IK CHOI ${ }^{1 *}$, BON HYEOCK KOO ${ }^{2 *}$, DONGEUI HONG ${ }^{1}$, HYUNG JOO KWON $^{3}$, KWANG LAE HOE $^{4}$, \\ MOO HO WON ${ }^{5}$, YOUNG MYEONG KIM ${ }^{6}$, HYUN KYO LIM ${ }^{1}$ and SUNGWOO RYOO ${ }^{2}$ \\ ${ }^{1}$ Department of Anesthesiology and Pain Medicine, Yonsei University Wonju College of Medicine, Wonju, Gangwon 26426; \\ ${ }^{2}$ Department of Biology, Kangwon National University, Chuncheon, Gangwon 24341; ${ }^{3}$ Department of Microbiology, \\ School of Medicine, Hallym University, Chuncheon, Gangwon 24252; ${ }^{4}$ New Drug Discovery and Development, \\ Chungnam National University, Daejeon 34134; Departments of ${ }^{5}$ Neurobiology, and ${ }^{6}$ Molecular and Cellular \\ Biochemistry, and Neurobiology, Kangwon National University, Chuncheon, Gangwon 24341, Republic of Korea
}

Received November 15, 2018; Accepted February 28, 2019

DOI: $10.3892 / \mathrm{mmr} .2019 .10035$

\begin{abstract}
The contractility of vascular smooth muscle cells (VSMCs) controls the lumen diameter of vessels, thus serving a role in regulating blood pressure and organ blood flow. Although arginases are known to have numerous effects in the biological activities of VSMCs, the effects of arginase II on the constriction of VSMCs has not yet been investigated. When conducting a natural products screen for an inhibitor against arginase, the present study identified that a relatively high concentration of resveratrol (RSV) exhibited arginase inhibitory activity. Therefore, the present study investigated whether RSV could regulate VSMCs contractions and the underlying mechanism. Arginase inhibition by RSV led to an increase in the concentration of the substrate L-Arg and an accompanying increase in the cytosol $\mathrm{Ca}^{2+}$ concentration $\left[\left(\mathrm{Ca}^{2+}\right) \mathrm{c}\right]$ in VSMCs. The increased $\left[\mathrm{Ca}^{2+}\right] \mathrm{c}$ induced by RSV and L-Arg treatments resulted in CaMKII-dependent MLC20 phosphorylation. The effects of RSV on VSMCs were maintained even when VSMCs were pre-treated with sirtinol, an inhibitor of Sirt proteins. In a vascular tension assay with de-endothelialized aortic vessels, vasoconstrictor responses, which were measured
\end{abstract}

Correspondence to: Professor Sungwoo Ryoo, Department of Biology, Kangwon National University, Kangwondae-gil 1, Chuncheon, Gangwon 24341, Republic of Korea

E-mail: ryoosw08@kangwon.ac.kr

Professor Hyun Kyo Lim, Department of Anesthesiology and Pain Medicine, Yonsei University Wonju College of Medicine, 20 Ilsan-ro, Wonju, Gangwon 26426, Republic of Korea

E-mail: hyunkyolim@yonsei.ac.kr

${ }^{*}$ Contributed equally

Key words: arginase inhibition, cytosolic $\mathrm{Ca}^{2+}$, resveratrol, vascular smooth muscle cells, vasoconstriction using phenylephrine (PE), were significantly enhanced in the RSV- and L-Arg-treated vessels. Therefore, although arginase inhibition has exhibited beneficial effects in various diseases, care is required when considering administration of an arginase inhibitor to patients with vessels endothelial dysfunction as RSV can induce vessel contraction.

\section{Introduction}

Arginase is the enzyme that functions in the last step of the urea cycle to hydrolyzes L-arginine (L-Arg) to L-ornithine and urea. The arginase isoforms, arginase I and II, are encoded by distinct genes, show $60 \%$ sequence homology, and exhibit different tissue distribution and subcellular localization patterns. Arginase I is a cytosolic enzyme that is abundantly expressed in the liver, whereas arginase II is a mitochondrial protein that is predominantly expressed in the kidney $(1,2)$. In addition to its primary function in the urea cycle, arginase exhibits various biological activities in vascular smooth muscle cells (VSMCs). In VSMCs of the rat carotid artery, inhibition or knockdown of arginase I led to attenuated medial and neointimal DNA synthesis and neointima formation (3). In mouse VSMCs, arginase II is involved in cell senescence and apoptosis (4). In our previous studies, we demonstrated that the proliferation of rat VSMCs, induced by the inflammatory cytokine, interleukin-1 $\beta$, was suppressed by inhibition of arginase in a cGMP-dependent manner (5). Inhibition of arginase II also inhibited $\mathrm{Ca}^{2+}$ uptake into the mitochondria of native low-density lipoprotein-stimulated human aortic smooth muscle cells, thus arginase II activity may regulate $\mathrm{Ca}^{2+}$ levels in the cytosol and the mitochondria (6). Furthermore, we recently reported that inhibition of arginase II activated endothelial nitric oxide synthase by increasing the cytosolic $\mathrm{Ca}^{2+}$ level $\left[\left(\mathrm{Ca}^{2+}\right)\right]$ in a p32-dependent manner (7).

The modulation of smooth muscle tone by various factors in the vasculature plays a role in the control of lumen diameter, which associated with blood pressure and organ blood flow (8-10). All smooth muscle cells produce force and 
contraction through cross-bridge cycling between actin and myosin filaments. The contraction response is the result of myosin-light chain kinase (MLCK) and myosin-light chain phosphatase (MLCP) activation. In VSMCs, this process is dependent on the $\mathrm{Ca}^{2+}$-mediated change in the myosin filaments (9). Increased intracellular $\mathrm{Ca}^{2+}$ is a primary target of the EF-hand $\mathrm{Ca}^{2+}$-binding protein calmodulin, and then the $\mathrm{Ca}^{2+} /$ calmodulin complex activates MLCK via $\mathrm{Ca}^{2+} /$ calmodulin-dependent protein kinase II (CaMKII) phosphorylation. Contraction can also occur independent of $\mathrm{Ca}^{2+}$ through the activation of the RhoA/Rho kinase pathway, which leads to MLCP inactivation and maintenance of the contraction (11).

Because the contractile activity of VSMCs plays an important role in the regulation of vascular tone in the vessels, its dysregulation can result in endothelial dysfunction leading to cardiovascular diseases. Therefore, identifying natural compounds that can effectively inhibit arginase to control this contractile activity would offer a new strategy for the treatment and prevention of vascular conditions. Resveratrol (RSV) is a small polyphenol found in grapes, berries, and peanuts, and is considered to protect against cardiovascular diseases by reducing platelet aggregation, low-density lipoprotein oxidation, prostagladin synthesis, and endothelial cells activation by tumor necrosis factor- $\alpha$, as well as by activating and inducing endothelial nitric oxide synthase (12-14). RSV has been known to activate to SirT proteins that post-translationally regulate protein activity by deacetylation, and RSV-dependent activation of SirT has showed a marked reduction in the signs of aging. On the other hand, inhibitors of SirT, such as sirtinol and splitomicin, were proposed to treat cancer and human immunodeficiency virus infection (15). Moreover, RSV was found to prevent angiotensin II-stimulated hypertrophy (16) and NADPH oxidase-dependent proliferation (17), as well as to induce differentiation to a contractile phenotype in VSMCs (18). However, the effect of RSV on the regulation of VSMCs contractility remains unknown. We hypothesized that RSV regulates VSMCs contractions by inhibiting arginase. To test this hypothesis, we treated rat VSMCs with RSV and determined the effects on arginase activity and $\left[\mathrm{Ca}^{2+}\right] \mathrm{c}$, as well as the effecs on contraction by evaluating the change in CaMKII-dependent MLC20 phosphorylation. We further determined the effects of RSV on vascular contractility using an ex vivo vessel tension assay with thoracic aortas of mice. Our results should highlighted the fundamental mechanisms of VSMCs contractility and the potential role of arginase inhibition as a clinical treatment.

\section{Materials and methods}

Materials. RSV (trans-1,2-(3,4', 5-Trihydroxydiphenyl) ethylene; Fig. 1) was purchased from Tokyo Chemical Industry inc. (Tokyo, Japan) and the purity was shown to be $\geq 99 \%$ by gas chromatographic analysis. 2(S)-amino-6-boronohexanoic acid $(\mathrm{ABH})$ was purchased from Calbiochem. Co. (La Jolla, CA, USA). All other reagents were purchased from Sigma unless otherwise stated.

VSMCs isolation and maintenance. Vascular smooth muscle cells (VSMCs) were isolated from the thoracic aortas and the upper parts of the abdominal aorta of 10-12-week old Sprague Dawley male rats $(n=4$, DBL Co., Chungbuk Korea) as previously described (19) with minor modifications. Briefly, the rat were anesthetized with isoflurane, aortas were stripped and cut into $2 \mathrm{~mm}$ pieces that were treated with $1 \mathrm{mg} / \mathrm{ml}$ of type II collagenase (Invitrogen; Thermo Fisher Scientific, Inc., Waltham, MA, USA) for $1 \mathrm{~h}$ to remove the endothelial cells, and then the cells were washed with the culture medum. The de-endothelialized pieces of aorta were incubated with culture medium in a gelatin $(0.1 \%)$-coated culture dish for approximately $10 \mathrm{~d}$. The VSMCs cultures were confirmed to be $>95 \%$ pure by immunocytochemical staining for $\alpha$-smooth muscle actin. VSMCs that were passaged 2-5 times were used in the subsequent experiments. The culture medium consisted of Dulbecco's modified Eagle's medium (DMEM) supplemented with $10 \%$ fetal bovine serum (FBS), $0.5 \mathrm{X}$ smooth muscle growth supplement (Cascade Biologics, Portland, OR, USA), $100 \mathrm{U} / \mathrm{ml}$ penicillin, $100 \mu \mathrm{g} / \mathrm{ml}$ streptomycin, $8 \mathrm{mM}$ HEPES, and $2 \mathrm{mM}$ glutamine. The VSMCs were cultured at $37^{\circ} \mathrm{C}$ in a humidified $5 \% \mathrm{CO}_{2}$ incubator.

Arginase activity assay and intracellular L-Arg quantification . Arginase activity was determined by quantifying the urea generated from L-Arg substrate as previously described (20). Intracellular concentrations of L-Arg were determined using high-performance liquid chromatography (HPLC) with pre-column derivatization with o-phthalaldehyde (OPA) according to a modification of previously published methods (21). Briefly, L-Arg (100 $\mu \mathrm{mol} / \mathrm{l})$ and polyamine (30 $\mu \mathrm{mol} / \mathrm{l} / \mathrm{each})$ were added to the cell lysate $(0.1 \mathrm{mmol} / \mathrm{l})$ as internal standard. The samples were extracted on solid-phase extraction cartridges (CBA Bond elute, Varian), with a recovery rate of $87.5 \pm 3.9 \%$ to $\mathrm{L}-\mathrm{Arg}$. The eluates were dried over nitrogen and resuspended in double-distilled water for HPLC analysis. HPLC was performed on a computer-controlled Waters chromatography system (M600E) consisting of an automatic injector (M7725i, Waters Co.) and a fluorescence detector (FP-1520, Jasco Co.). Samples were incubated for $1 \mathrm{~min}$ with OPA reagent $(5.4 \mathrm{mg} / \mathrm{ml}$ OPA in borate buffer, $\mathrm{pH} 8.4$, with $0.4 \%$ 2-mercaptoethanol) before automatic injection into the HPLC system. The OPA derivatives of L-Arg and polyamine were separated on a $150 \times 4.6 \mathrm{~mm}-5 \mu \mathrm{m}$ Zorbax Eclipse XDB-C18 column with the fluorescence detector set at an excitation of $340 \mathrm{~nm}$ and an emission of $450 \mathrm{~nm}$. Samples were eluted from the column with $0.96 \%$ citric acid:methanol (70:30), $\mathrm{pH} 6.8$, at a flow rate of $1.5 \mathrm{ml} / \mathrm{min}$.

Cytosolic $\mathrm{Ca}^{2+}$ measurement using confocal microscopy and flow cytometry. Direct assessment of the $\left[\mathrm{Ca}^{2+}\right] \mathrm{c}$ was peformed using an established procedure in which cells were loaded with the fluorescent agent Fluo-4 AM (ThermoFisher Scientific Co., Waltham, MA). Briefly, the cells were incubated with $100 \mathrm{nmol} / 1$ Fluo-4 AM at $37^{\circ} \mathrm{C}$ for $1 \mathrm{~h}$ in a starvation medium. The cells were then washed to remove excess Fluo-4 AM and incubated in Tyrode's modified solution $(150 \mathrm{mmol} / \mathrm{l} \mathrm{NaCl}$, $4 \mathrm{mmol} / 1 \mathrm{KCl}, 2 \mathrm{mmol} / 1 \mathrm{CaCl}_{2}, 2 \mathrm{mmol} / 1 \mathrm{MgCl}_{2}, 10 \mathrm{mmol} / \mathrm{l}$ HEPES, and $10 \mathrm{mmol} / \mathrm{l}$ glucose). For detection of Fluo-4 AM fluorescence, $494 \mathrm{~nm}$ excitation, and $506 \mathrm{~nm}$ emission filters were used. Intensity values were normalized according to the initial fluorescence values after subtraction of the background signal using the Metamorph program (Molecular Probe). The $\left[\mathrm{Ca}^{2+}\right] \mathrm{c}$ was also determined using flow cytometry on a FACS 


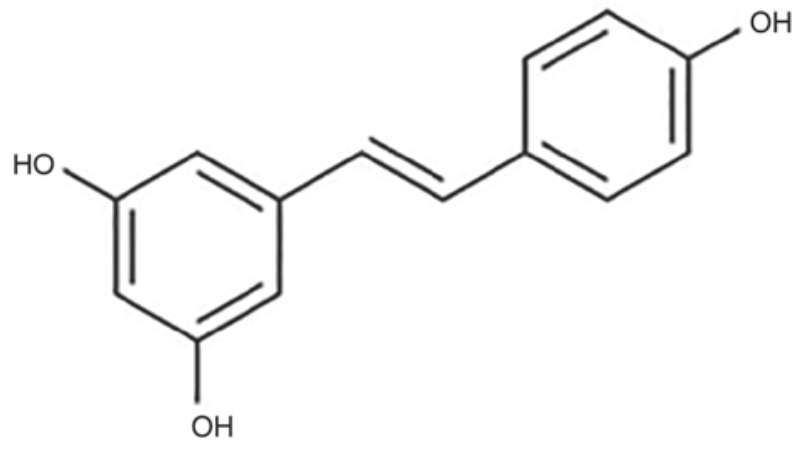

Figure 1. Structure of reversatrol.

Calibur system. The fluorescence intensity for each sample was determined using CellQuest software, and the $\mathrm{Ca}^{2+}$ level was calculated by comparing the fluorescence intensities of treated cells vs. control cells.

MTT assay. The cytotoxic activities of the tested compounds were measured using MTT 3 (4,5-dimethylthiazol-2-yl)-2,5-diphenyltetrazolium bromide-based colorimetric assay. MTT was purchased from Sigma. In brief, $1 \times 10^{4}$ cells per well were seeded in 96-well plates and allowed to grow for $24 \mathrm{~h}$. The tested compounds were added to the wells at the indicated concentrations and the plates were incubated for an additional $48 \mathrm{~h}$. Then, MTT solution $(5 \mathrm{mg} / \mathrm{ml})$ was added and the plates were incubated for an additional $4 \mathrm{~h}$. The experiment was performed in triplicate and cell viability was determined by measuring the optical density at $570 \mathrm{~nm}$.

Western blotting analysis. Cells were lysed in SDS sample buffer (62.5 mmol/1 Tris, pH 6.8, 2\% SDS, and 10\% glycerol) and sonicated for $5 \mathrm{sec}$ to reduce sample viscosity. Each sample was resolved by $10 \%$ SDS-PAGE, and transferred to PVDF membranes (Bio-Rad Laboratories, Inc., Hercules, CA, USA). Membranes were incubated with primary antibodies against phospho-CaMKII, CaMKII, phospho-MLC20, and MLC-20 (BD Biosciences, San Jose, CA) according to the manufacturer's protocol and were visualized with peroxidase and enhanced chemiluminescence (Thermo Fisher Scientific, Inc.). The phosphorylation levels of the proteins were normalized to the total protein levels. Densitometry analysis of bands was performed using ImageJ software (National Institute of Health, Bethesda, MD, USA).

Vascular tension assay. Thoracic aortas were dissected from C57BL/6 mice that had been anesthetized with isoflurane, and the fat and connective tissues were removed from the aortas. The aortas were cut into $1.5-\mathrm{mm}$ rings, and endothelia were gently removed using a wooden stick. The aorta sections were then suspended between two wire stirrups $(150 \mu \mathrm{m})$ in $10 \mathrm{ml}$

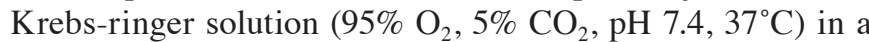
myograph (Multi myograph system DMT-620). One stirrup was connected to a three-dimensional micromanipulator, and the other was connected to a force transducer. The rings were passively stretched in 100-mg increments at $10-\mathrm{min}$ intervals to reach the optimal tone $(600 \mathrm{mg})$. After the arterial rings had been stretched to their optimal resting tone, the contractile response to $100 \mathrm{mM} \mathrm{KCl}$ was determined. Responses to the maximal $\mathrm{KCl}$ dose were used to normalize the agonist responses across vessel rings. Dose responses to the vasoconstrictor phenylephrine $\left(\mathrm{PE} ; 10^{-10}-10^{-6} \mathrm{M}\right)$ were also determined.

Statistical analysis. Data are reported as the mean \pm SD. Statistical significance was determined using the Bonferroni-corrected unpaired t test for unpaired values. A P-value $<0.05$ was considered statistically significance. Dose responses were analyzed using two-way or one-way analysis of variance (ANOVA) followed by Bonferroni's post-hoc test, using Graphpad prism 5.0 software.

\section{Results}

$R S V$ shows arginase inhibitory activity. Arginase I and II solutions were prepared from liver and kidney lysates, respectively, and ability of RSV to inhibit arginase activity was measured. RSV inhibited arginase I and II activities in a dose-dependent manner (Fig. 2A and B). At $50 \mu \mathrm{mol} / 1$ of RSV, the residual activities of arginase I and arginase II were $75.1 \pm 1.8$ and $82.5 \pm 5.8 \%$, respectively. However, $\mathrm{ABH}$, a known arginase inhibitor, strongly inhibited arginase I and II activity at only

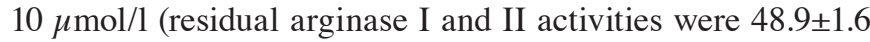
and $43.1 \pm 2.6 \%$, respectively). Because effects have preiously been observed with $20 \%$ inhibition of arginase activity (20), we used $50 \mu \mathrm{mol} / 1 \mathrm{RSV}$ for subsequent experiments. In VSMCs culture and in de-endothelialized aortic vessels of mice, $50 \mu \mathrm{mol} / 1 \mathrm{RSV}$ inhibited arginase activity $38.7 \pm 3.1$ and $32.0 \pm 1.3 \%$, respectively (Fig. 2C and D).

Treatment with RSV increased the intracellular level of L-Arg, thereby raising the $\left[\mathrm{Ca}^{2+}\right] c$ in VSMCs. Because inhibition of arginase induced CaMKII phosphorylation (22), we determined whether treatment of RSV would change the $\left[\mathrm{Ca}^{2+}\right] \mathrm{c}$ level. Both RSV and $\mathrm{ABH}$ treatments increased the $\left[\mathrm{Ca}^{2+}\right] \mathrm{c}$ in VSMCs as observed by microscopy (Fig. 3A; *vs. untreated, $\mathrm{P}<0.05$; untreated, 60.6 $\pm 10.6 \%$; RSV $50 \mu \mathrm{mol} / 1,100 \pm 2.8 \%$ ) and real-time measurement (Fig. 3B; ${ }^{*} \mathrm{P}<0.05$ ). Treatment with RSV also increased the intracellular L-Arg concentration in VSMCs (Fig. 3C; *vs. untreated, $\mathrm{P}<0.05$; untreated, $100.0 \pm 2.8 \%$; RSV $50 \mu \mathrm{mol} / 1,128.5 \pm 9.6 \%$ ). To confirm the effect of arginase inhibition on the $\left[\mathrm{Ca}^{2+}\right] \mathrm{c}$, we examined the change in $\left[\mathrm{Ca}^{2+}\right] \mathrm{c}$ following treatment with L-Arg using flow cytometry. Incubation with L-Arg significantly increased the $\left[\mathrm{Ca}^{2+}\right] \mathrm{c}$ in a dose-dependent manner, and BAPTA-AM significantly attenuated the fluorescent signal of Fluo-4 AM (Fig. 3D; *vs. untreated, $\mathrm{P}<0.05$, untreated vs. L-Arg at $10^{-6} \mathrm{~mol} / 1,37.0 \pm 5.0$ vs. $\left.72.0 \pm 3.5 \%\right)$. These results indicated that the increased intracellular L-Arg concentration, which results from arginase inhibition by $\mathrm{RSV}$, plays a crucial role in the augmentation of $\left[\mathrm{Ca}^{2+}\right] \mathrm{c}$. In addition, $\mathrm{RSV}, \mathrm{ABH}$, and L-Arg, did not show cytoxic effects on VSMCs (Fig. 3E, ns, not significant).

CaMKII activation by RSV associated with MLC20 phosphorylation. Because RSV increased the $\left[\mathrm{Ca}^{2+}\right] \mathrm{c}$ by an L-Arg-dependent mechanism, we examined whether RSV may activate CaMKII. Indeed, $50 \mu \mathrm{mol} / 1 \mathrm{RSV}$ induced 

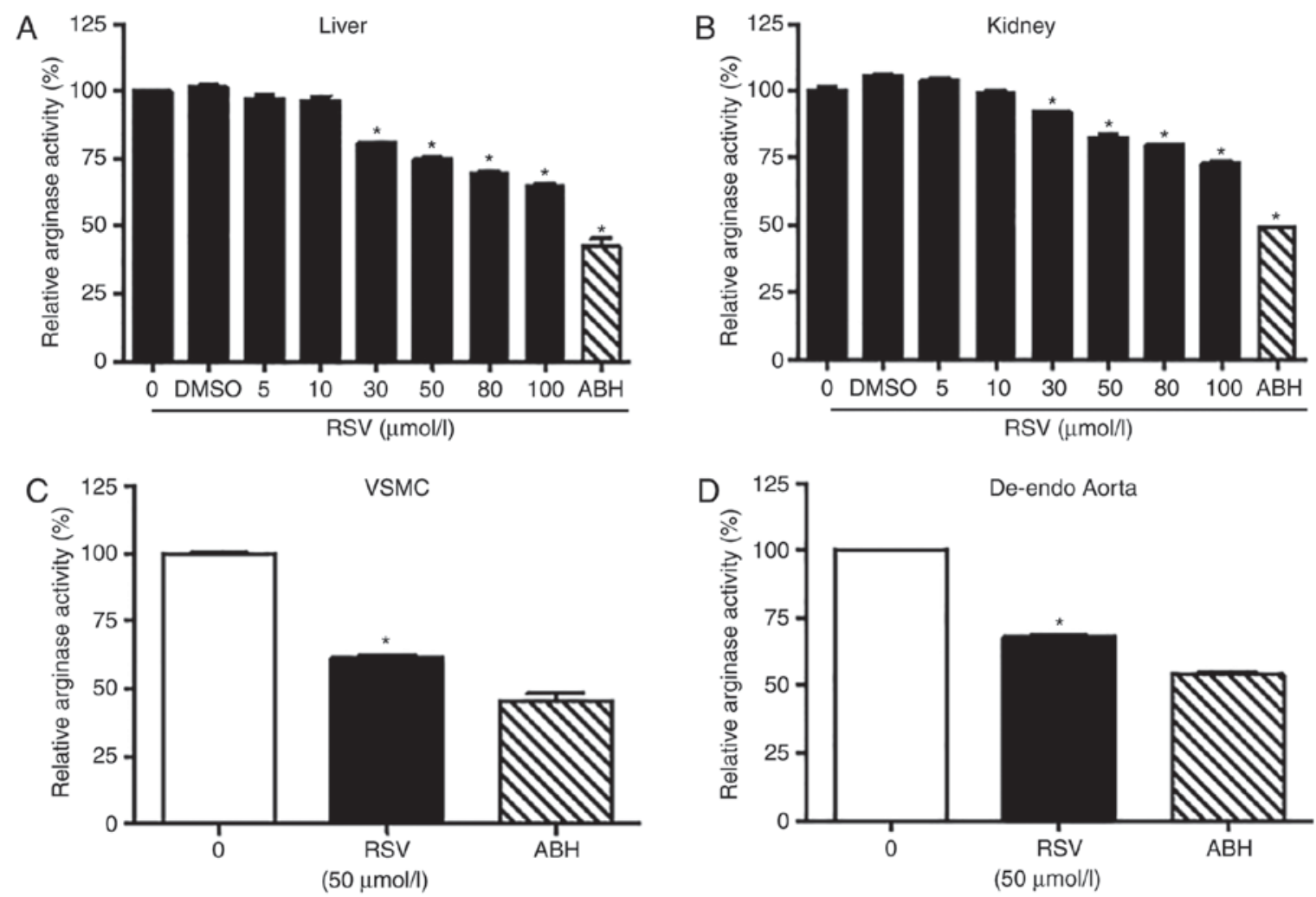

Figure 2. Inhibition of arginase activity by reversatrol. (A) Liver and (B) kidney lysates were prepared and used as arginase I and II enzyme solutions, respectively. Arginase activity was measured in the presence of different concentrations of RSV ( $\mathrm{P}<0.01)$. Arginase activity was measured in (C) VSMCs and (D) de-endothelialized aortic vessels treated with $50 \mu \mathrm{mol} / 1$ of RSV and $10 \mu \mathrm{mol} / 1 \mathrm{ABH}$, a known arginase inhibitor, for $12 \mathrm{~h}$. ${ }^{*} \mathrm{P}<0.01 \mathrm{vs}$. untreated control. $\mathrm{n}=4$ independent experiments.

CaMKII phosphorylation at Thr286 (Fig. 4A; *vs. untreated, $1.0 \pm 0.1$ vs. $3.5 \pm 0.2 \mathrm{AU}, \mathrm{P}<0.05)$, which associated with phosphorylation of MLC20 (Fig. 4B, *vs. untreated, $1.0 \pm 0.2$ vs. $3.6 \pm 0.3 \mathrm{AU}, \mathrm{P}<0.05$; Fig. $4 \mathrm{C}$, * vs. untreated, $1.0 \pm 0.1$ vs. $2.2 \pm 0.2 \mathrm{AU}, \mathrm{P}<0.05$; ${ }^{*} \mathrm{vs}$. RSV, $1.8 \pm 0.1$ vs. $2.2 \pm 0.2 \mathrm{AU}$, $\mathrm{P}<0.01)$. Consistently, incubation of VSMCs with L-Arg also increased the phosphorylation of CaMKII Thr286 (Fig. 4D, ${ }^{*} \mathrm{~L}-\mathrm{Arg}(1 \mathrm{mmol} / \mathrm{l})$ vs. untreated, $1.6 \pm 0.2$ vs. $1.0 \pm 0.1 \mathrm{AU}$, $\mathrm{P}<0.05$; ${ }^{*}$ vs. L-Arg $(1 \mathrm{mmol} / \mathrm{l}), 0.57 \pm 0.1$ vs. $1.6 \pm 0.2 \mathrm{AU}$, $\mathrm{P}<0.01)$ and MLC20 (Fig. 4E; ${ }^{*} \mathrm{~L}-\mathrm{Arg}(1 \mathrm{mmol} / \mathrm{l})$ vs. untreated, $1.6 \pm 0.2$ vs. $1.0 \pm 0.01 \mathrm{AU}, \mathrm{P}<0.05)$. We also tested whether the effect of RSV may be derived from activation of Sirt proteins by treating in VSMCs with RSV and sirtinol, an inhibitor of Sirt proteins, and we found that the RSV-induced changes in CaMKII and MLC20 phosphorylation levels were not influenced by sirtinol (Fig. 4F; phospho-CaMKII, *vs. untreated control, $1.7 \pm 0.2$ vs. $1.0 \pm 0.1 \mathrm{AU}, \mathrm{P}<0.01,{ }^{*} \mathrm{vs}$. RSV, $1.7 \pm 0.2$ vs. $1.5 \pm 0.15 \mathrm{AU}$, not significant; phospho-MLC20, "vs. untreated control, $1.8 \pm 0.1$ vs. $1.0 \pm 0.01 \mathrm{AU}, \mathrm{P}<0.01,{ }^{*} \mathrm{vs}$. RSV, $1.8 \pm 0.1$ vs. $1.8 \pm 0.1 \mathrm{AU}$, not significant).

RSV augmented vessel constriction in de-endothelialized aortas. Because RSV treatment increased MLC20 phosphorylation in VSMCs, we measured the effect of RSV on vascular tension using de-endothelialized aortas of wild-type (WT) mice. The de-endothelialized aortic vessels did not respond to the endothelium-dependent vasorelaxant acetylcholine (Ach, Fig. 5A). However, dose responses to PE (Fig. 5B), an endothelium-independent vasoconstrictor, were enhanced in
RSV-treated vessels (Emax, WT + de-endo vs. WT + RSV + de-endo, Emax, $179.2 \pm 6.6$ vs. $253.4 \pm 9.8 \%, \log \mathrm{EC}_{50},-7.3 \pm 0.1$ vs. $\left.-7.2 \pm 0.1 \mathrm{~mol} / 1,{ }^{*} \mathrm{P}<0.05\right)$, and preincubation with $10 \mu \mathrm{mol} / 1$ of sirtinol did not change the RSV-induced effects (Emax, $\mathrm{WT}+\mathrm{RSV}$ vs. WT + RSV + sitinol, Emax, $253.4 \pm 9.8$ vs. $275.4 \pm 9.7 \%, \log \mathrm{EC}_{50},-7.2 \pm 0.1$ vs. $-7.2 \pm 0.1 \mathrm{~mol} / 1$, not significant). Interestingly, treatment of de-endothelialized aortic vessels of WT mice with L-Arg induced vasoconstriction [Fig. 5C; L-Arg (10-5 mol/l) vs. PE-preconstriction, $86.6 \pm 12.0$ vs. $100 \pm 0.1 \%$; L-Arg $\left(10^{-4} \mathrm{~mol} / \mathrm{l}\right)$ vs. PE-preconstriction, $79.4 \pm 13.2$ vs. $\left.100 \pm 0.1 \%,{ }^{*} \mathrm{P}<0.05\right]$ ]. However, there was no significant difference in the dose responses to the nitric oxide (NO) donor sodium nitroprusside (SNP) among the treatment groups (Fig. 5D). Additionally, the vasoconstrictive effect of RSV did not differ upon short-term incubation $(4 \mathrm{~h})$ and long-term incubation (16 h).

\section{Discussion}

In this study, we demonstrated that RSV at relatively higher concentrations inhibited arginase I and II activities and consequently increased the concentration of the substrate, L-Arg. Interestingly, RSV also increased $\left[\mathrm{Ca}^{2+}\right] \mathrm{c}$ in VSMCs in a manner dependent on the L-Arg concentration. The increased $\left[\mathrm{Ca}^{2+}\right] \mathrm{c}$ led to CaMKII-dependent MLC20 phosphorylation, which was mimicked with L-Arg stimulation in VSMCs. These RSV-induced effects were maintained when VSMCs were treated with sirtinol, an inhibitor of Sirt proteins. Moreover, in a vascular tension assay with de-endothelialized aortic vessels, 
A

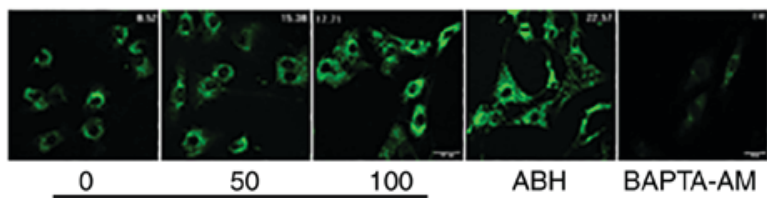

RSV $(\mu \mathrm{mol} / \mathrm{l})$
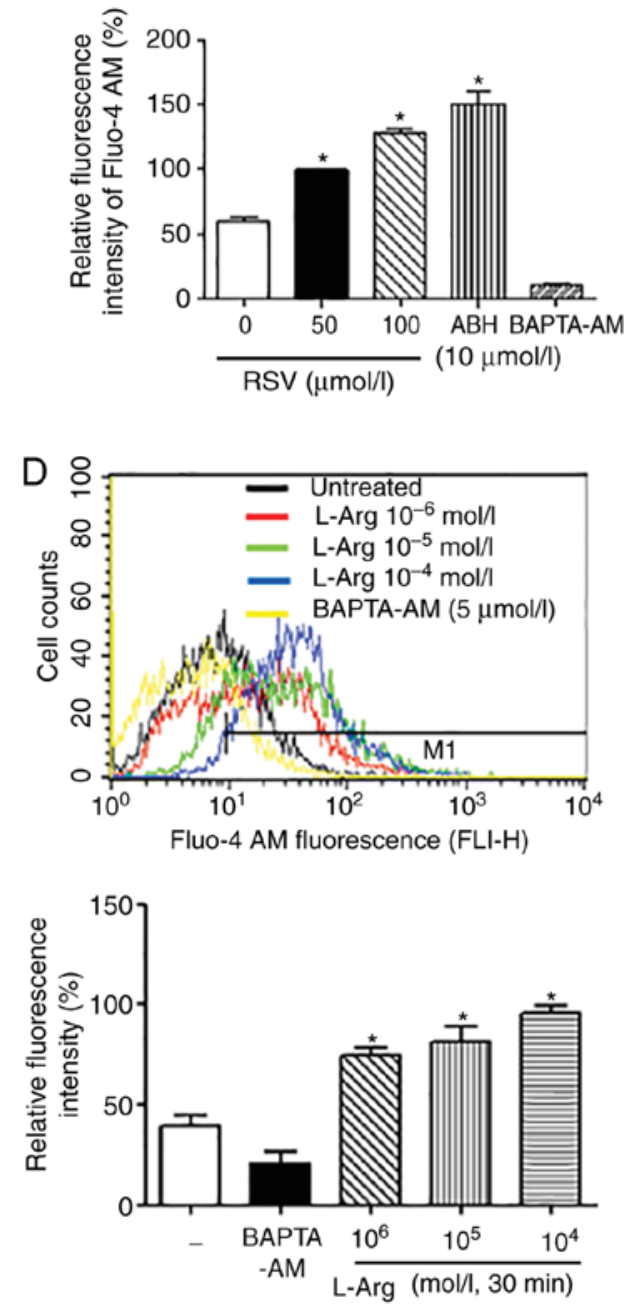
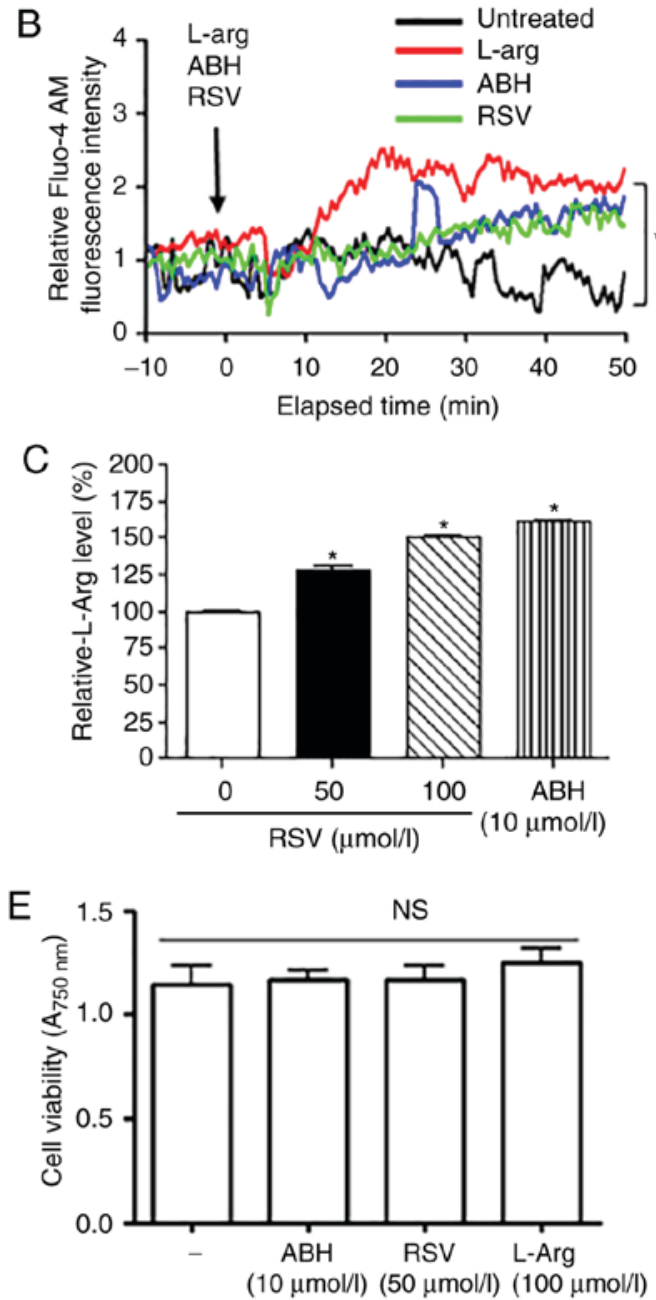

Figure 3. RSV-induced inhibition of arginase led to increase in $\left[\mathrm{Ca}^{2+}\right] \mathrm{c}$ in an L-Arg-dependent manner. VSMCs were pre-treated with RSV and ABH for $30 \mathrm{~min}$ and then stained with Fluo-4 AM to measure $\left[\mathrm{Ca}^{2+}\right] \mathrm{c}$. Representative image (A) and real-time measurement scale bar $10 \mu \mathrm{M}$ (B) to Fluo-4 fluorescence intensity are shown. (C) Intracellular L-Arg concentration was analyzed using HPLC and presented as a bar graph. (D) [Ca $\left.{ }^{2+}\right] \mathrm{c}$ was examined in cells that were pre-treated with L-Arg (30 min) by FACS analysis. BAPTA-AM (5 $\mu \mathrm{mol} / 1,30 \mathrm{~min})$ was used as an intracellular Ca ${ }^{2+}$ chelating agent. (E) Cell viability was measured using the MTT assay after cells were treated with various agents for $24 \mathrm{~h} .{ }^{*} \mathrm{P}<0.05$ vs. untreated control. ns, not significant, $\mathrm{n}=4$ independent experiments.

vasoconstrictor responses to PE were significantly enhanced in both RSV- and L-Arg-treated vessels.

An increase in the level of L-Arg, which results from arginase inhibition, is beneficial because L-Arg augments endothelial NO production, which regulates vasoreactivity, platelet activation, adhesion molecules expression, monocytes infiltration into the intima, apoptosis of endothelial cells, and proliferation and migration of VSMCs. We previously reported that inhibition of arginase II suppresses proliferation of VSMCs, which were stimulated with native low-density lipoprotein, through NADPH oxidase inactivation (23) and interleukin-8 production through p38 MAPK inactivation (6). However, L-Arg supplementation exhibited harmful effects for phathophysiological conditions, such as diabetic nephropathy (24), hypertension (25), and peripheral artery disease (26). Consistent with these findings, in this study, we found that arginase inhibition with RSV led to vessels constriction, which may cause aggravation of a pathological condition in vasculature with endothelial dysfunction.

RSV, a polyphenol molecule containing two phenyl rings connected by a methylene bridge (Fig. 1), was the first compound discovered that could mimic calorie restriction that occurs when sirtuins are stimulated $(27,28)$. Treatment of RSV was shown to improves the general health of mice that were fed high-calorie diet (29); these mice showed a marked reduction in the signs of aging, including reduced albuminuria and cataracts formation, decreased inflammation and apoptosis in the vascular endothelium, increased aortic elasticity, greater motor coordination, and preserved bone mineral density (30). 
A
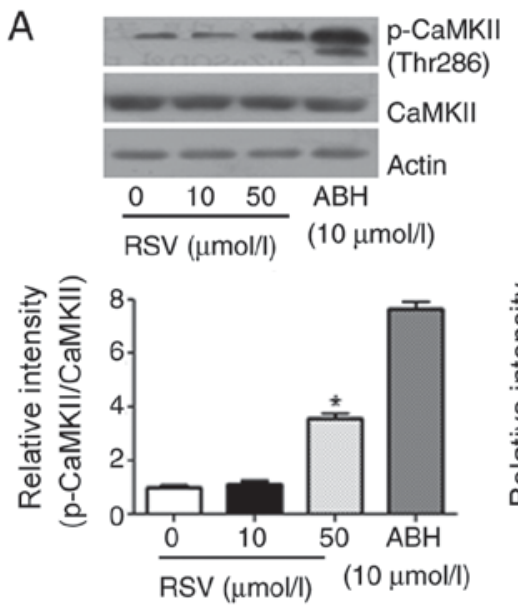

D
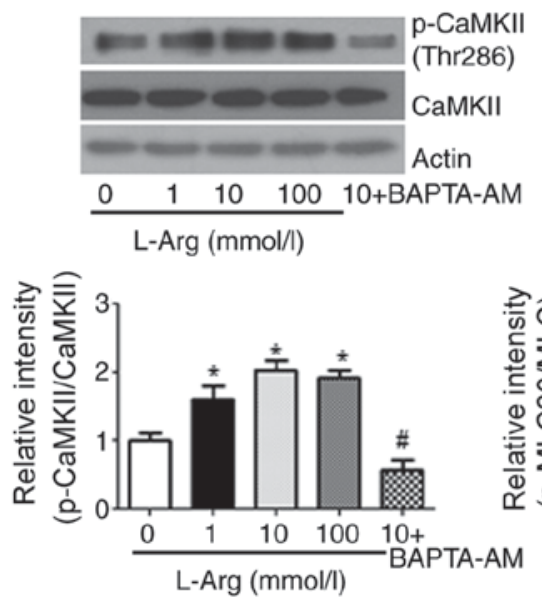

$B$
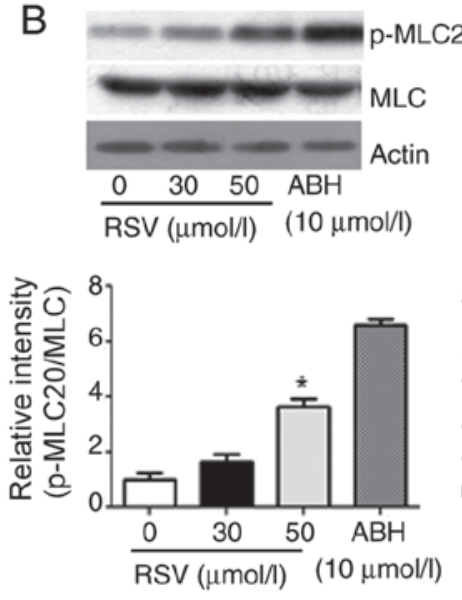

E

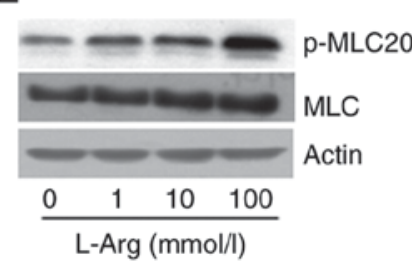

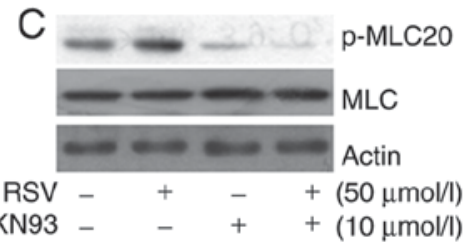

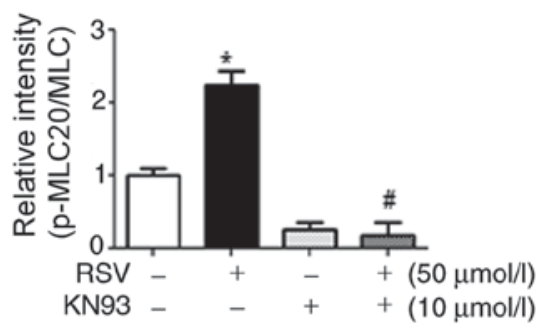

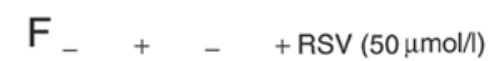

$-\quad+\quad+\quad+$ Sirtinol $(100 \mu \mathrm{mol} / \mathrm{l})$
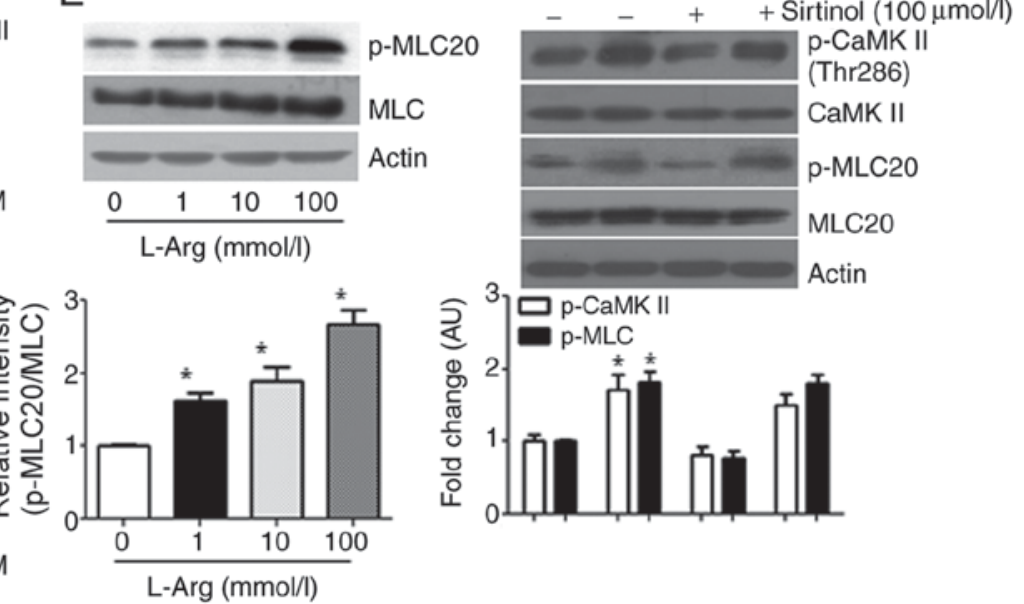

Figure 4. RSV and L-Arg induced MLC-20 phosphorylation. Western blots of CaMKII activation (A) and MLC-20 phosphorylation (B) in lysates of VSMCs that were preincubated with RSV for $30 \mathrm{~min}$. MLC-20 phosphoryaltion was also tested in the presence of KN93 (10 $\mu$ mol/1, 30 min), an inhibitor of CaMKII. (C) Different concentrations of L-Arg were incubated with VSMCs for 30 min, and CaMKII activation (D) and MLC-20 phosphorylation (E) were analyzed. BAPTA-AM (5 $\mu \mathrm{mol} / 1,30 \mathrm{~min})$ was used as a control. The data in the bar graphs represent the results of 4 independent experiments. *vs. untreated control, $\mathrm{P}<0.05$. "vs. RSV, P<0.01. (F) VSMCs were pre-incubated with the Sirt inhibitor sirtinol for 30 min, and the effect of RSV on CaMKII-dependent MLC20 phosphorylation was examined. ${ }^{*} \mathrm{P}<0.01 \mathrm{vs}$. untreated control. $\mathrm{n}=4$ independent experiments. AU, arbitrary unit.

Furthermore, RSV has been shown to have several effects on VSMCs (16-18), however, these studies used various RSV concentrations and found different concentration-dependent effects. In one study, at a low dose of RSV, VSMCs differentiation was found to be induced by SirT1-dependent Akt2 activation, whereas a high dose of RSV stimulated AMPK, which inhibited the mTORC1 pathway, thereby relieving the S6K1 inhibition and allowing Akt activation and the induction of differentiation (18). Although RSV can induce a multiple signaling cascades, the molecular target of RSV at a high dose has not been clearly demonstrated to date. Here, we demonstrate that arginase II, which regulates the mTORC1/S6K1 cascade and AMPK pathway, may be a target of RSV at a high concentration (31).

In VSMCs, $\left[\mathrm{Ca}^{2+}\right] \mathrm{c}$ is required to maintain the basal vascular tone, which is modulated by $\mathrm{Ca}^{2+}$ release from the intracellular stores in the sarcoplasmic reticulum and mitochondria and by $\mathrm{Ca}^{2+}$ entry from the extracellular space through $\mathrm{Ca}^{2+}$ channels in the plasma membrane. We found that RSV increased the $\left[\mathrm{Ca}^{2+}\right] \mathrm{c}$ and the L-Arg level by inhibiting arginase (Fig. 3). Previously, RSV was associated with intracellular
$\mathrm{Ca}^{2+}$ signaling because of the direct rise in $\left[\mathrm{Ca}^{2+}\right] \mathrm{c}$ (32-34), which was proposed to originate from the intracellular $\mathrm{Ca}^{2+}$ store (33). Interestingly, the endoplasmic reticulum (ER) $\mathrm{Ca}^{2+}$ content in prostate cancer cell lines PC 3 and DU145 decreased upon treatment with RSV (35). Collectively, these findings suggest that RSV increases in $\left[\mathrm{Ca}^{2+}\right] \mathrm{c}$ through activation of the $\mathrm{IP}_{3}$ receptor in the ER.

Polyphenols, such as RSV (3,4',5-trihydroxystilbene) and piceatannol (3,3',4',5-tetrahydroxystilbene, a hydroxylated analogue of RSV), are secondary metabolites present in many fruits, vegetables, and medicinal plants. Numerous epidemiological and experimental studies strongly indicate their potential in the treatment of chronic diseases, including vascular and cardiac diseases, obesity, diabetes, and cancer. The positive effects of polyphenols are partly due to increase in NO production (36). In our previous studies, piceatannol inhibited the activity of arginase isoforms and reciprocally regulated the NO production by endothelial NO synthase (37). Because piceatannol showed stronger arginase inhibitory activity than RSV, it may be useful to compare two polyphenols for structure-based drug design. RSV is generally 

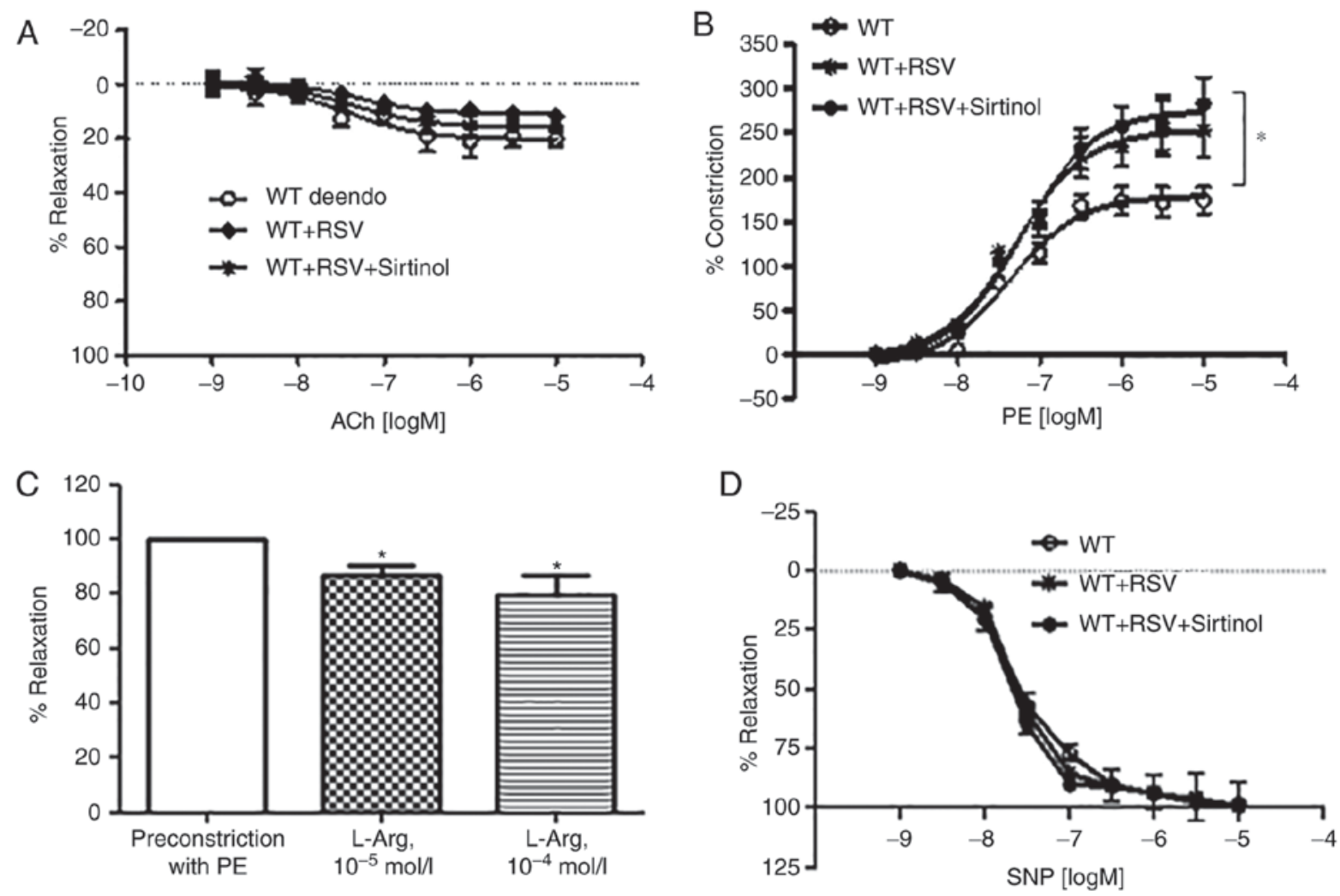

Figure 5. RSV increased vasoconstrictive activity in de-endothelialized vessels. De-endothelialized aortic vessels from WT mice (A) were incubated with RSV $(50 \mu \mathrm{mol} / 1,16 \mathrm{~h})$, and contractile responses to phenylephrine (PE) were analyzed $(\mathrm{B}){ }^{*} \mathrm{P}<0.05$. $\mathrm{n}=8$ vessels from 3 mice. $(\mathrm{C})$ De-endothelialized aortic rings were pre-constrited with $\mathrm{PE}\left(10^{-6} \mathrm{~mol} / \mathrm{l}\right)$ for $10 \mathrm{~min}$ and then treated with different concentration of L-Arg for $1 \mathrm{~h}$. The final responses were showed. $\mathrm{P}<0.05$ vs. untreated control, $\mathrm{n}=16$ rings from 8 mice. (D) Endothelium-independent relaxation responses were measured with SNP treatment. $\mathrm{n}=9$ rings from 4 mice.

accepted as a beneficial natural product to treat cardiovascular disorders because increases production of NO, which is a vasoprotective molecule. The maximal concentration of $\mathrm{RSV}$ in commercial red wine was reported to be $11.2 \mathrm{mg} / \mathrm{l}$ (37), which is equivalent to $50 \mu \mathrm{mol} / \mathrm{l}$. However, patients with vascular disorders, such as hypertension, should be careful when taking RSV because RSV may exacerbate blood pressure as shown in this study. However, in healthy obese man, $150 \mathrm{mg} /$ day of a nutraceutical formulation RSV has been shown to have beneficial effects, which mimic the effects of calorie restriction (38).

In conclusion, RSV at a high concentration inhibited arginase activity and increased the L-Arg level leading to enhanced $\mathrm{Ca}^{2+}$ signaling by the activation of CaMKII in VSMCs. In turn, RSV-dependent CaMKII activation elicited MLC20 phosphorylation that augmented vasoconstriction in de-endothelialized vessels; however, Sirt protein activation by RSV was not involved in the $\mathrm{Ca}^{2+}$-dependent constriction. Therefore, although arginase inhibition has shown beneficial effects for various diseases, care is required when considering the administration of an arginase inhibitor to patients with vessels with endothelial dysfunction.

\section{Acknowledgements}

The authors would like to thank the Central Laboratory of Kangwon National University (Chuncheon, Korea) for technical assistance with the instruments.

\section{Funding}

This study was supported by the Basic Science Research Program of the National Research Foundation of Korea (NRF) funded by the Ministry of Education, Science and Technology (grant nos. 2015M3A9B6066968, 2016M3A9B6903185 and 2018R1D1A1B07047959), and by a 2017 Research Grant from Kangwon National University (grant no. 2017-S.R).

\section{Availability of data and materials}

The datasets used and/or analyzed during the current study are available from the corresponding author on reasonable request.

\section{Authors' contributions}

CIC, BHK, and DH performed the experiments. HJK, KLH, $\mathrm{MHW}$, and YMK analyzed the data and wrote the manuscript. HKL and SR designed the study and wrote the manuscript.

\section{Ethics approval and consent to participate}

All experiments were performed with approval of the Ethics Committee of Kangwon National University (Chuncheon, Korea).

\section{Patient consent for publication}

Not applicable. 


\section{Competing interests}

The authors declare that they have no competing interests.

\section{References}

1. Morris SM Jr: Arginine metabolism: Boundaries of our knowledge. J Nutr 137 (6 Suppl 2): 1602S-1609S, 2007.

2. Pernow $\mathbf{J}$ and Jung $\mathrm{C}$ : Arginase as a potential target in the treatment of cardiovascular disease: Reversal of arginine steal? Cardiovasc Res 98: 334-343, 2013.

3. Peyton KJ, Ensenat D, Azam MA, Keswani AN, Kannan S, Liu XM, Wang H, Tulis DA and Durante W: Arginase promotes neointima formation in rat injured carotid arteries. Arterioscler Thromb Vasc Biol 29: 488-494, 2009.

4. Xiong Y, Yu Y, Montani JP, Yang Z and Ming XF: Arginase-II induces vascular smooth muscle cell senescence and apoptosis through p66Shc and p53 independently of its 1-arginine ureahydrolase activity: Implications for atherosclerotic plaque vulnerability. J Am Heart Assoc 2: e000096, 2013.

5. Yoon $J$ and Ryoo S: Arginase inhibition reduces interleukin-1 $\beta$-stimulated vascular smooth muscle cell proliferation by increasing nitric oxide synthase-dependent nitric oxide production. Biochem Biophys Res Commun 435: 428-433, 2013.

6. Koo BH, Yi BG, Jeong MS, Kwon SH, Hoe KL, Kwon YG, Won MH, Kim YM and Ryoo S: Arginase II inhibition prevents interleukin-8 production through regulation of p38 MAPK phosphorylation activated by loss of mitochondrial membrane potential in nLDL-stimulated hAoSMCs. Exp Mol Med 50: e438, 2018

7. Koo BH, Hwang HM, Yi BG, Lim HK, Jeon BH, Hoe KL, Kwon YG, Won MH, Kim YM, Berkowitz DE and Ryoo S: Arginase II contributes to the $\mathrm{Ca} 2+/ \mathrm{CaMKII} / \mathrm{eNOS}$ axis by regulating $\mathrm{Ca} 2+$ concentration between the cytosol and mitochondria in a p32-dependent manner. J Am Heart Assoc 7: e009579, 2018.

8. Jackson WF: Ion channels and vascular tone. Hypertension 35: $173-178,2000$

9. Hilgers RH and Webb RC: Molecular aspects of arterial smooth muscle contraction: Focus on Rho. Exp Biol Med (Maywood) 230: 829-835, 2005

10. Woodrum DA and Brophy CM: The paradox of smooth muscle physiology. Mol Cell Endocrinol 177: 135-143, 2001.

11. Wynne BM, Chiao CW and Webb RC: Vascular smooth muscle cell signaling mechanisms for contraction to angiotensin II and endothelin-1. J Am Soc Hypertens 3: 84-95, 2009.

12. Schmitt CA and Dirsch VM: Modulation of endothelial nitric oxide by plant-derived products. Nitric Oxide 21: 77-91, 2009.

13. Opie LH and Lecour S: The red wine hypothesis: From concepts to protective signalling molecules. Eur Heart J 28: 1683-1693, 2007.

14. Leifert WR and Abeywardena MY: Cardioprotective actions of grape polyphenols. Nutr Res 28: 729-737, 2008.

15. Villalba JM and Alcain FJ: Sirtuin activators and inhibitors. Biofactors 38: 349-359, 2012.

16. Haider UG, Sorescu D, Griendling KK, Vollmar AM and Dirsch VM: Resveratrol suppresses angiotensin II-induced Akt/protein kinase B and p70 S6 kinase phosphorylation and subsequent hypertrophy in rat aortic smooth muscle cells. Mol Pharmacol 62: 772-777, 2002.

17. Ushio-Fukai M, Griendling KK, Becker PL, Hilenski L, Halleran S and Alexander RW: Epidermal growth factor receptor transactivation by angiotensin II requires reactive oxygen species in vascular smooth muscle cells. Arterioscler Thromb Vasc Biol 21: 489-495, 2001.

18. Thompson AM, Martin KA and Rzucidlo EM: Resveratrol induces vascular smooth muscle cell differentiation through stimulation of SirT1 and AMPK. PLoS One 9: e85495, 2014.

19. Wang Y, Lindstedt KA and Kovanen PT: Mast cell granule remnants carry LDL into smooth muscle cells of the synthetic phenotype and induce their conversion into foam cells. Arterioscler Thromb Vasc Biol 15: 801-810, 1995.

20. Ryoo S, Gupta G, Benjo A, Lim HK, Camara A, Sikka G, Lim HK, Sohi J, Santhanam L, Soucy K, et al: Endothelial arginase II: A novel target for the treatment of atherosclerosis. Circ Res 102: 923-932, 2008.
21. Böger RH, Bode-Böger SM, Mügge A, Kienke S, Brandes R, Dwenger A and Frölich JC: Supplementation of hypercholesterolaemic rabbits with L-arginine reduces the vascular release of superoxide anions and restores NO production. Atherosclerosis 117: 273-284, 1995.

22. Nguyen MC and Ryoo S: Intravenous administration of piceatannol, an arginase inhibitor, improves endothelial dysfunction in aged mice. Korean J Physiol Pharmacol 21: 83-90, 2017.

23. Koo BH, Yi BG, Wang WK, Ko IY, Hoe KL, Kwon YG, Won MH, Kim YM, Lim HK and Ryoo S: Arginase inhibition suppresses native low-density lipoprotein-stimulated vascular smooth muscle cell proliferation by NADPH oxidase inactivation. Yonsei Med J 59: 366-375, 2018.

24. You H, Gao T, Cooper TK, Morris SM Jr and Awad AS: Diabetic nephropathy is resistant to oral L-arginine or L-citrulline supplementation. Am J Physiol Renal Physiol 307: F1292-F1301, 2014.

25. Brooks WW, Conrad CH, Robinson KG, Colucci WS and Bing OH: L-arginine fails to prevent ventricular remodeling and heart failure in the spontaneously hypertensive rat. Am J Hypertens 22: 228-234, 2009.

26. Wilson AM, Harada R, Nair N, Balasubramanian N and Cooke JP: L-arginine supplementation in peripheral arterial disease: No benefit and possible harm. Circulation 116: 188-195, 2007.

27. Wood JG, Rogina B, Lavu S, Howitz K, Helfand SL, Tatar M and Sinclair D: Sirtuin activators mimic caloric restriction and delay ageing in metazoans. Nature 430: 686-689, 2004.

28. Howitz KT, Bitterman KJ, Cohen HY, Lamming DW, Lavu S, Wood JG, Zipkin RE, Chung P, Kisielewski A, Zhang LL, et al: Small molecule activators of sirtuins extend Saccharomyces cerevisiae lifespan. Nature 425: 191-196, 2003.

29. Baur JA, Pearson KJ, Price NL, Jamieson HA, Lerin C, Kalra A, Prabhu VV, Allard JS, Lopez-Lluch G, Lewis K, et al: Resveratrol improves health and survival of mice on a high-calorie diet. Nature 444: 337-342, 2006.

30. Pearson KJ, Baur JA, Lewis KN, Peshkin L, Price NL, Labinskyy N, Swindell WR, Kamara D, Minor RK, Perez E, et al: Resveratrol delays age-related deterioration and mimics transcriptional aspects of dietary restriction without extending life span. Cell Metab 8: 157-168, 2008.

31. Xiong Y, Yepuri G, Forbiteh M, Yu Y, Montani JP, Yang Z and Ming XF: ARG2 impairs endothelial autophagy through regulation of MTOR and PRKAA/AMPK signaling in advanced atherosclerosis. Autophagy 10: 2223-2238, 2014.

32. Sareen D, Darjatmoko SR, Albert DM and Polans AS: Mitochondria, calcium, and calpain are key mediators of resveratrol-induced apoptosis in breast cancer. Mol Pharmacol 72: 1466-1475, 2007.

33. Garcia-Sanchez L, Santofimia-Castaño P, Miro-Moran A, Tapia JA, Salido GM and Gonzalez A: Resveratrol mobilizes $\mathrm{Ca} 2+$ from intracellular stores and induces c-Jun N-terminal kinase activation in tumoral AR42J cells. Mol Cell Biochem 362: 15-23, 2012.

34. Chang HJ, Chou CT, Chang HT, Liang WZ, Hung TY, Li YD, Fang YC, Kuo CC, Kuo DH, Shieh P and Jan CR: Mechanisms of resveratrol-induced changes in cytosolic free calcium ion concentrations and cell viability in OC2 human oral cancer cells. Hum Exp Toxicol 34: 289-299, 2015.

35. Selvaraj S, Sun Y, Sukumaran P and Singh BB: Resveratrol activates autophagic cell death in prostate cancer cells via downregulation of STIM1 and the mTOR pathway. Mol Carcinog 55: 818-831, 2016.

36. Bordage S, Pham TN, Zedet A, Gugglielmetti AS, Nappey M, Demougeot $C$ and Girard-Thernier C: Investigation of mammal arginase inhibitory properties of natural ubiquitous polyphenols by using an optimized colorimetric microplate assay. Planta Med 83: 647-653, 2017.

37. Woo A, Min B and Ryoo S: Piceatannol-3'-O-beta-Dglucopyranoside as an active component of rhubarb activates endothelial nitric oxide synthase through inhibition of arginase activity. Exp Mol Med 42: 524-532, 2010.

38. Timmers S, Konings E, Bilet L, Houtkooper RH, van de Weijer T, Goosens GH, Hoeks J, van der Krieken S, Ryu D, Kersten S, et al: Calorie restriction-like effects of 30 days of resveratrol supplementation on energy metabolism and metabolic profile in obese humans. Cell Metab 14: 612-622, 2011. 